\title{
Yoga for Health: Why Should it be Practiced?
}

\author{
Bruno Gonçalves Galdino da Costa* and Kelly Samara da Silva \\ Research Center for Physical Activity and Health, Federal University of Santa Catarina, Brazil
}

Submission: April 26, 2017; Published: May 23, 2017

*Corresponding author: Bruno Gonçalves Galdino da Costa, Research Center for Physical Activity and Health, Federal University of Santa Catarina, Santa Catarina, Brazil, Room 048, Tel: 55- 48-999285288; 55- 48 -3721-8519; Email: bruno.g.costa@posgrad.ufsc.br

\begin{abstract}
Yoga has become a popular exercise worldwide. The benefits of practicing Yoga regularly are similar of other exercises when analyzing gains in strength, balance and flexibility. In addition to its physical benefits Yoga also promotes other cognitive benefits, and its mechanisms and pathways are yet to be unveiled.
\end{abstract}

Keyword: Yoga; Motor activity; Public health

\section{Introduction}

Yoga's history is rich and its roots are deep into the religious and shamanistic culture of Hinduism and Indian history [1] More recently, Yoga has been used to improve people's health and as an alternative physical activity for people to engage in their free time. Although its roots are similar, many schools of Yoga were derived from its original practice, with some, like Hatha Yoga, becoming popular forms of exercise worldwide [2]. Due to the many postures, which often require strength, flexibility and balance to be achieved and maintained, practicing Yoga regularly can benefit health and physical fitness [2].

The regular practice of Yoga provides organic adaptations that help to treat and protect a number of outcomes such as depression [3-5], anxiety disorders [6] asthma [7] knee arthritis [8] and compromised hemodynamic function [9,10]. The benefits of Yoga are still being discovered and studies have to be replicated in order to confirm and understand the physiological and psychological pathways that provide each adaptation.

Most health benefits cited above could be achieved by other exercises such as sports and gymnastics, which also provides adaptations to cardiovascular, muscular and bone systems, and should be practiced by everyone [11]. The Compendium of Physical Activities [12], which composes a wide database of energy expenditure of many forms of physical activities measured with gold standard instruments, shows that Hatha Yoga has an average energy expenditure of 2.5 metabolic equivalent (METs), that is, each minute practicing it, the person will burn 2.5 times the same energy he would spend while resting. Similarly, Yoga practiced with instruction videos poses a lighter effort, with an average 2.3 METs, while Power Yoga provides a more intense experience with 4 METs. In addition, Nadisodhana Yoga provides an average effort of 2 METs and Surya Namaskar Yoga of 3.3 METs. Compared to these forms of Yoga, many simple exercises could provide a more intense experience to the practitioner, some examples are moderate callisthenic exercises (3.8 METs) such as push-ups, pull-ups, and sit-ups, or moderate-intensity circuit training (4.3 METs), and resistance training (6 METs).

We know that many forms of exercises could provide physiological stimuli that are similar to those performed in Yoga sessions, which are necessary for the organism to adapt. While many modalities focus on providing an intense training for strength or aerobic fitness, Yoga might contribute to the enhancement of these capacities and at the same time providing additional benefits that are not easily observed or measured. Yoga also provides lifestyle lessons, that promotes mediation, self-knowledge, consciousness and attention, and the ability not to relax just the body, but as a whole [13]. Under this scope, Yoga could offer additional benefits to its practitioner that other modalities such as resistance training might not, helping coping with daily stress [13], anxiety [6] and promoting overall wellbeing [14] by including on each session cognitive and emotional aspects in parallel to the physical effort associated with the postures.

It is important to note that many aspects of Yoga are yet being researched [15] and randomized controlled trials need to 
be replicated in order to provide evidence of its effectiveness. For those who might engage in Yoga as a treatment for anxiety and depression, it is important to always be in accordance to professional medical prescriptions as some studies show that Yoga is most effective when combined with medication [6].

\section{Conclusion}

The regular practice of Yoga can benefit people's health and improve physical fitness, but it also provides more benefits by promoting cognitive stimuli that helps dealing with stress, anxiety and psychological disorders. Although more research is necessary to better understand the pathways and mechanisms thru which Yoga provides such benefits, scientific evidence up to date supports that promoting Yoga practice could help populations live a better and healthier life.

\section{References}

1. Padhi MM (2016) Evolution of Yoga and Physiotherapy. J Yoga Physioterapy.

2. Tran MD, Holly RG, Lashbrook J, Amsterdam EA (2001) Effects of Hatha Yoga Practice in the Health-Related Aspects of Physical Fitness. Prev Cardiol 4(4): 165-70.

3. Uebelacker LA, Tremont G, Gillette LT, Epstein LG, Strong DR, et al. (2017) Adjunctive yoga v. Health education for persistent major depression: a randomized controlled trial. Psychol Med 6: 1-13.

4. Prathikanti S, Rivera R, Cochran A, Tungol JG, Fayazmanesh N, et al. (2017) Treating major depression with yoga: A prospective, randomized, controlled pilot trial. PLoS One 12(3): e0173869.
5. Pilkington K, Kirkwood G, Rampes H, Richardson J (2005) Yoga for depression: The research evidence. J Affect Disord 89(1-3): 13-24.

6. da Silva TL, Ravindran LN, Ravindran AV (2009) Yoga in the treatment of mood and anxiety disorders: A review. Asian J Psychiatr 2(1): 6-16.

7. Chen TL, Mao HC, Lai CH, Li CY, Kuo CH (2009) The effect of yoga exercise intervention on health related physical fitness in school-age asthmatic children. Hu Li Za Zhi 56(2): 42-52.

8. Cheung C, Wyman JF, Bronas U, McCarthy T, Rudser K, et al. (2017) Managing knee osteoarthritis with yoga or aerobic/strengthening exercise programs in older adults: a pilot randomized controlled trial. Rheumatol Int 37(3): 389-698.

9. Parshad O, Richards A, Asnani M (2011) Impact of yoga on haemodynamic function in healthy medical students. West Indian Med J 60(20): 148-152.

10. Hunter SD, Dhindsa MS, Cunningham E, Tarumi T, Alkatan M, Nualnim $\mathrm{N}$, et al. (2016) Impact of Hot Yoga on Arterial Stiffness and Quality of Life in Normal and Overweight/Obese Adults. J Phys Act Health 13(12): 1360-1363.

11. WHO (2010) Global recommendations on physical activity and health World Health Organization, Geneva, Swizerland.

12. Ainsworth BE, Haskell WL, Herrmann SD, Meckes N, Bassett DR, et al. (2011) 2011 Compendium of Physical Activities: a second update of codes and MET values. Med Sci Sports Exerc 43(8): 1575-1581.

13. Singh VK (2016) Message of yoga to humanity. J Yoga Physioterapy.

14. Hadi N, Hadi N (2007) Effects of hatha yoga on well-being in healthy adults in Shiraz, Islamic Republic of Iran. East Mediterr Health J 13(4): 829-837.

15. Siegel P, de Barros NF (2017) Research on Yoga: Still a Long Way to Go. J Yoga Physioterapy.

\section{Your next submission with Juniper Publishers will reach you the below assets}

- Quality Editorial service

- Swift Peer Review

- Reprints availability

- E-prints Service

- Manuscript Podcast for convenient understanding

- Global attainment for your research

- Manuscript accessibility in different formats ( Pdf, E-pub, Full Text, Audio)

- Unceasing customer service

Track the below URL for one-step submission https://juniperpublishers.com/online-submission.php 